\title{
Aqueous humor cytokine levels through microarray analysis and a sub-analysis based on optical coherence tomography in wet age-related macular degeneration patients
}

\author{
Jin-Ho Joo ${ }^{1}$, Hyejee Kim², Jae-Ho Shin ${ }^{1}$ and Sang Woong Moon ${ }^{1 *}$
}

\begin{abstract}
Background: To identify disease-specific cytokine and growth factor profile differences in the aqueous humor between wet age-related macular degeneration (AMD) patients and age-matched controls and to correlate their levels with the optical coherence tomography (OCT) findings.

Methods: Aqueous humors were obtained from 13 wet AMD eyes and 10 control eyes. Twenty cytokines and growth factors were measured using a RayBio antibody microarray technology in wet AMD and control eyes.

Results: The samples obtained from wet AMD patients exhibited a significantly increased expression of MCP-1, MIP-1a, MIP-1 $\beta$, and vascular endothelial growth factor (VEGF). Subretinal fluid (SRF) patients showed significantly lower levels of proinflammatory cytokines, such as IL-1 a and GM-CSF, than those without SRF. Pigment epithelial detachments (PED) patients showed lower levels of inflammatory cytokines, such as GM-CSF, IFN- $\gamma$, and TNF-a, than those without PED. Subretinal tissue (SRT) patients showed a higher level of IFN- $\gamma$ than those without SRT. Compared with the controls, type 1 macular neovascularization (MNV) patients showed increased levels of MCP-1, MIP-1a, and MIP-1 $\beta$, but not VEGF ( $p=0.083$ ). However, type 2 MNV patients showed increased levels of MCP-1 and VEGF $(p=0.040$ and $p=0.040)$.

Conclusion: Inflammatory cytokines varied according to the type of AMD- and OCT-based parameters. Our observation of low levels of VEGF in patients with type 1 MNV implies that the inhibition of VEGF alone appears to be insufficient treatment for these patients and that cytokines such as MCP-1, MIP-1a, and MIP-1 $\beta$ should be modulated. And the presence of SRF in MNV may be associated with a positive prognosis because we found relatively low levels of proinflammatory cytokines.
\end{abstract}

Keywords: AMD, Aqueous humor, Cytokine, OCT

\section{Background}

Wet age-related macular degeneration (AMD) is the leading cause of irreversible visual impairment in the elderly in developed countries. The involvement of vascular

*Correspondence: ophmoon@gmail.com

${ }^{1}$ Department of Ophthalmology, Kyung Hee University Hospital at Gangdong, 892 Dongnam-ro, Gangdong-gu, Seoul, Republic of Korea

Full list of author information is available at the end of the article endothelial growth factor (VEGF) in AMD has been strongly supported in several studie $s[1-3]$. VEGF seems to be the major stimulus of neovascular growth originating from the retinal and choroidal vasculatur e[4]. The advent of intravitreal anti-VEGF therapy has introduced a new standard of treatment for patients with wet AM $\mathrm{D}[1]$.. original author(s) and the source, provide a link to the Creative Commons licence, and indicate if changes were made. The images or other third party material in this article are included in the article's Creative Commons licence, unless indicated otherwise in a credit line to the material. If material is not included in the article's Creative Commons licence and your intended use is not permitted by statutory regulation or exceeds the permitted use, you will need to obtain permission directly from the copyright holder. To view a copy of this licence, visit http://creativecommons.org/licenses/by/4.0/. The Creative Commons Public Domain Dedication waiver (http://creativeco mmons.org/publicdomain/zero/1.0/) applies to the data made available in this article, unless otherwise stated in a credit line to the data. 
However, anti-VEGF treatment limitations partly arise from the profound heterogeneity found in the profiles of individual patients with choroid neovascularization $(\mathrm{CNV})$ and partly arise from the insufficient effects of the anti-VEGF treatment. Although some patients may perform well with few intravitreal anti-VEGF injections, in some patients, the $\mathrm{CNV}$ lesion continues to progress and recur despite the monthly injection $s[1,5,6]$. Further, it is widely accepted that anti-VEGF treatment improves the vision of patients, but it may not cure or stop the disease proces $s[7]$. Other studies have revealed elevated concentrations of other cytokines, including VEGF, in the aqueous humor, vitreous, and retinas of eyes with neovascular disorder $s[8-10]$. In addition to anti-VEGF injections, the intravitreal administration of anti-inflammatory substances, such as triamcinolone, a widely used anti-inflammatory drug, has also shown positive effects in treating $\mathrm{CNV}$ patient s[11]. Knowledge of factors that mediate intraocular neovascular processes is important for the development of new treatment strategies.

We aimed to investigate the possible roles of various cytokines and growth factors in the pathogenesis of AMD by comparing the aqueous humor levels of 20 cytokines in eyes with cataracts and eyes with AMD. We also investigated the correlation of morphologic information based on optical coherence tomography (OCT) between cytokine information in eyes with AMD.

\section{Methods}

This prospective trial was performed at the Department of Ophthalmology at Kyunghee University. The protocol was approved by the Ethics Committee of Kyunghee University Hospital at Gangdong (2015-07-042-014) and followed the tenets of the Helsinki protocol. Informed consent was obtained from all patients before being included in the study.

\section{Patient selection}

We included patients with wet AMD of two subtypes of macular neovascularization (MNV); occult type, type 1 and classic type, type 2 type. Two subtypes were classified through fluorescein angiography (FA) pattern. The fluorescein angiographic appearance of classic type consists of a discrete, well-demarcated focal area of hyperfluorescence that can be discerned in the early phases of the angiogram. Occult type refers to fibrovascular pigment epithelial detachment and late choroidal-based leakage patterns on $\mathrm{F} \mathrm{A}[12]$. Only patients with recentonset disease (treatment-naïve patients) were included in the study. All patients with wet AMD underwent comprehensive ophthalmic examinations, including best-corrected visual acuity (Snellen was converted to logMAR, Logarithm of the Minimum Angle of Resolution), slit-lamp biomicroscopy with a +90-diopter lens, color fundus photography, FA, indocyanine green angiography, and OCT. All eyes with wet AMD had active lesions with exudative OCT changes. We excluded patients with any previous history of MNV lesion treatment, those who had undergone previous intraocular surgery (except for cataract surgery), any other type of retinal disease, glaucoma, or having an axial length $>26.5 \mathrm{~mm}$.

\section{Control group}

Controls were age-matched patients undergoing cataract surgery. We excluded patients with any type of retinal disease, glaucoma, uveitis, or a previous history of intraocular surgery.

\section{Acquisition of the aqueous humor samples}

Aqueous humor samples were obtained at the beginning of cataract surgery in the controls and immediately before the intravitreal injection in the eyes with wet AMD via limbal paracentesis. After topical anesthesia, approximately $100 \mu \mathrm{L}$ of aqueous humor were withdrawn using a 1-cc syringe and a 30-G needle at the limbus. The humor samples were immediately frozen and stored at $-80^{\circ} \mathrm{C}$ until the cytokine measurements.

\section{Measurement of cytokines}

We used antibody microarray technology. Samples were analyzed using RayBio ${ }^{\circledR}$ Quantikine Array kits (RayBiotech, Inc., GA, USA). These kits are used for the detection of IL-1a, IL-1b, IL-2, IL-4, IL-5, IL-6, IL-8, IL-10, IL-12p70, IL-13, granulocyte monocyte colony-stimulating factor (GM-CSF), GRO, IFN- $\gamma$, MCP- 1, MIP- $1 \alpha$, MIP-1 $\beta$, MMP-9, RANTES, TNF- $\alpha$, and VEGF. A volume of $50-100 \mu \mathrm{L}$ of undiluted aqueous humor samples was added to the arrays and these were incubated at room temperature for $1-2 \mathrm{~h}$. We used these kits to identify more inflammatory cytokines, other than VEGF, in wet AMD patients. The arrays were continually washed at room temperature using gentle rocking for $20 \mathrm{~min}$. The detection antibody cocktail was added to each well and incubated at room temperature for $1-2 \mathrm{~h}$. We added $80 \mu \mathrm{L}$ of $\mathrm{Cy} 3$ equivalent dye-conjugated streptavidin to each well, which was then incubated at room temperature for $1 \mathrm{~h}$. We used an array-specific Q-Analyzer, an Excel-based program, to perform sophisticated data analysis.

\section{Quantitative analysis of OCT images}

We measured the biomarkers in OCT images: the volume of subretinal fluid (SRF), the pigment epithelial detachments (PED), and the subretinal tissue (SRT) using Image $\mathrm{J}$ medical imaging software (National Institutes of Health, Bethesda, MD, USA). The boundary line for 
measuring the cross-sectional area of SRF, PED, and SRT in the OCT image was directly drawn by two ophthalmologists using Image J software, and the average value was measured. The boundary of the SRF was drawn along the boundary of the fluid between the sensory retina and the retinal pigment epithelium (RPE). The SRT was constructed along the boundary of the atypical fibrovascular proliferation in the subretinal space of the highly reflective region on the PRE. SRT was measured from the inner border of subretinal highly reflective material (comprising CNV, fibrosis, or hemorrhage) or fibrovascular pigment epithelial detachment or from the inner RPE layer border when no subretinal material was present, to Bruch's membrane. (see Additional file 1 )[13] The PED was set as the boundary between the inner surface of the elevated retinal pigment epithelium and the virtual normal RPE line. After that, the volume of each morphological element was calculated by accumulating the OCT images at $240-\mu \mathrm{m}$ intervals.

\section{Statistical analysis}

We used Mann-Whitney U test to compare the differences between groups. Correlations between cytokines and VEGF levels were assessed using Spearman's rank correlation. $P$ values lower than 0.05 were considered statistically significant. Statistical analysis was performed using SPSS statistical package 25.0 (IBM, Armonk, New York, USA).

\section{Results}

We included a total of 13 eyes of 13 treatment-naïve wet AMD patients that were compared to 10 age-matched control eyes of 10 participants. The demographic and baseline characteristics of the patients are listed in Table 1. The mean age of wet AMD patients and the controls was $74.2 \pm 6.83$ and $72.7 \pm 5.12$ years, respectively. There were no statistical differences regarding the age and sex distributions between the two groups $(p=0.364$, $p=0.420$ ). The mean visual acuity was $0.7 \log$ MAR in the wet AMD group and 0.4 $\operatorname{logMAR}$ in the control group, showing a statistically significant difference $(p<0.01)$. From the 13 naive wet AMD patients, 8 were type 1 (occult) MNV and 5 were type 2 (classic) MNV patients. In the wet AMD group, the number of eyes with SRF, PED, and SRT was 9,8 , and 8 , respectively (Table 1 ).

\section{Concentration of cytokines and growth factors}

Among the 20 cytokines, the levels of MCP-1 (also known as C-C motif chemokine 2; CCL2), MIP-1 $\alpha$ (CCL3), MIP-1 $\beta$ (CCL4), and VEGF were significantly increased in the wet AMD group compared with the control group $(p=0.003, p=0.041, p=0.034$, and $p=0.009)$ (Fig. 1$)$. The other cytokines were also detectable in all samples
Table 1 Baseline characteristics and demographics of patients with wet age-related macular degeneration (AMD) and controls

\begin{tabular}{lllr}
\hline & $\begin{array}{l}\text { AMD group } \\
(\boldsymbol{n}=\mathbf{1 3})\end{array}$ & $\begin{array}{l}\text { Control group } \\
(\boldsymbol{n}=\mathbf{1 0})\end{array}$ & $\boldsymbol{P}^{*}$ \\
\hline Mean age, years & $74.2 \pm 6.83$ & $72.7 \pm 5.12$ & 0.364 \\
$\begin{array}{l}\text { Gender, M/F (\%) } \\
\text { Mean baseline }\end{array}$ & $5 / 8(62.5 \%)$ & $3 / 7(42.9 \%)$ & 0.420 \\
$\begin{array}{l}\text { BCVA, logMAR } \\
\text { (range) }\end{array}$ & & $0.4(0.00$ to 1.00) & $<0.01$ \\
AMD type (no. of eyes) & & \\
$\quad$ & & \\
$\quad$ Type 1 & 8 & & \\
$\quad$ Type 2 & 5 & & \\
Presence of SRF & 9 & & \\
Presence of PED & 8 & & \\
Presence of SRT & 8 &
\end{tabular}

$B C V A$ best corrected visual acuity, SRF subretinal fluid, $P E D$ pigment epithelial detachment, SRT subretinal tissue

${ }^{*}$ Mann-Whitney U test

but were not significantly different between patients and controls. The concentration of VEGF was correlated with the concentration of many other inflammatory cytokines, such as ILs, RANTES, and TNF- $\alpha$, but not with the concentration of MCP-1 and MIP-1s (Table 2).

\section{Intraocular cytokines and OCT-based retinal morphology in wet $A M D$ patients}

The wet AMD patient groups were subdivided according to the OCT components. There were nine wet AMD patients with SRF and four wet AMD patients without SRF. The nine patients with MNV and SRF showed significantly lower levels of proinflammatory cytokines, such as IL- $1 \alpha$ and GM-CSF, compared with patients with MNV without SRF $(p=0.036$, and $p=0.05)$. Moreover, it was confirmed that there was a statistically significant negative correlation between the volume of SRF and the concentration of IL-1 $\alpha$ (Fig. 2).

Similar phenomena were also observed in patients with PED. Patients with PED showed relatively low levels of inflammatory cytokines, such as GM-CSF, IFN- $\gamma$, and TNF- $\alpha$, compared with those without PED $(p=0.006$, $p=0.034$, and $p=0.011$ ). In contrast, patients with SRT showed a relatively high level of IFN- $\gamma$ compared with those without SRT $(p=0.045)$ (Table 3$)$. There was no statistically significant correlation between the volume of PED and SRT and the cytokine levels.

\section{Levels of cytokines according to wet AMD classification}

We classified patients with wet AMD into two groups. Eight eyes of eight patients were classified as type $1 \mathrm{MNV}$, and five eyes of five patients were classified as type $2 \mathrm{MNV}$. When the OCT parameters were 
MCP-1

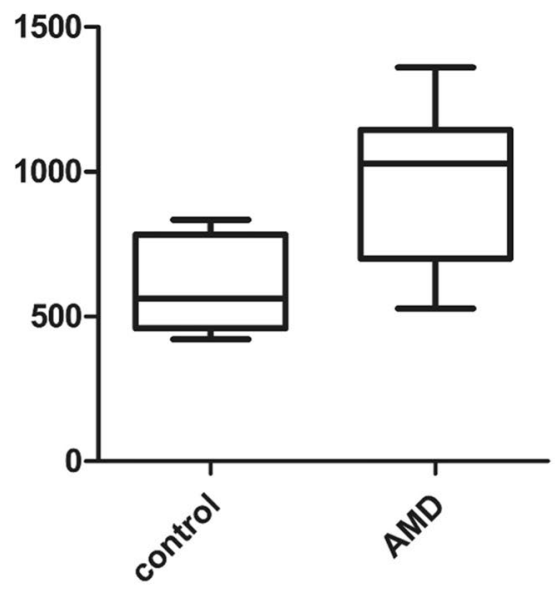

MIP-1b

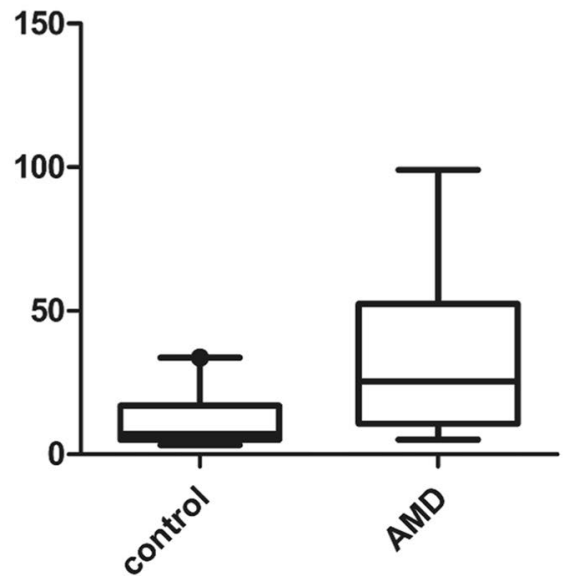

MIP-1a

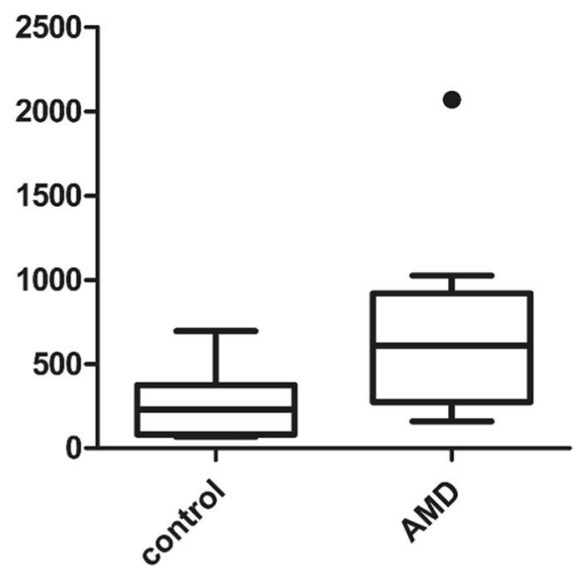

VEGF

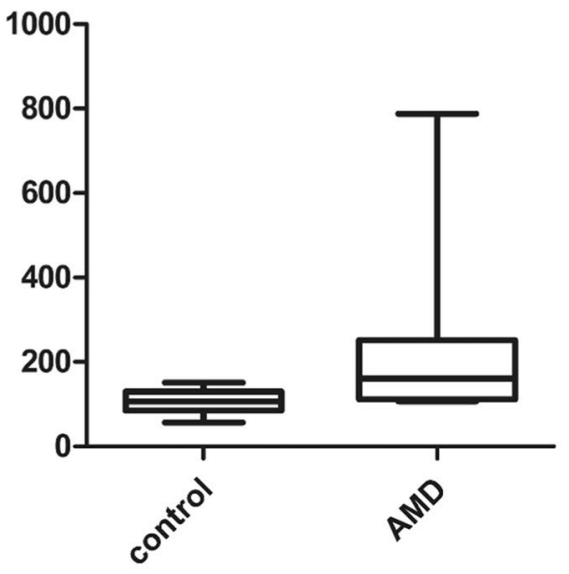

Fig. 1 Median concentration of MCP-1, MIP-1a, MIP-1 $\beta$, and vascular endothelial growth factor (VEGF) $(\mathrm{pg} / \mathrm{mL})$ in controls and patients with wet age-related macular degeneration (AMD)

compared in the type 1 and type 2 MNV groups, the average SRF volume value was larger in the type 1 MNV group, and the PED volume, SRT volume and central macular thickness (CMT) were larger in the type $2 \mathrm{MNV}$ group. However, all these parameters did not show a statistically significant difference. (Table 4).

Compared with the control group, the type $1 \mathrm{MNV}$ group showed increased levels of MCP-1, MIP-1 $\alpha$, and MIP- $1 \beta,(p=0.001, p=0.02$, and $p=0.012)$, but not of VEGF $(p=0.083)$. Meanwhile, the type $2 \mathrm{MNV}$ group showed increased levels of MCP-1 and VEGF $(p=0.040$, and $p=0.040)$. Patients with type $1 \mathrm{MNV}$ showed relatively low concentrations of INF- $\gamma$ and TNF- $\alpha$ compared to those with type $2 \mathrm{MNV}(p=0.006$, and $p=0.019$ ) (Table 5).

\section{Discussion}

We investigated various cytokine and angiogenic factors associated with aqueous humor. The vitreous sample would be more appropriate than the aqueous sample because it better reflects the state of the retina in AMD patients. Nevertheless, obtaining samples from the vitreous is dangerous and may cause adverse effects, such as vitreous hemorrhage, retinal detachment, endophthalmitis, among others. There may be differences in the concentration of immune mediators between the aqueous and the vitreous humor. However, the collection of samples from the aqueous humor is safer and easier, and similar levels have been reported in both the aqueous and vitreous humor s[14-16]. Immune mediators in the aqueous humor likely explain the presence of immune 
Table 2 Cytokine profile $(\mathrm{pg} / \mathrm{mL}$, mean \pm SD) and correlation between the concentration of cytokines and vascular endothelial growth factor (VEGF)

\begin{tabular}{|c|c|c|c|c|c|}
\hline & wAMD group $(n=13)$ & Control group $(n=10)$ & $p^{*}$ & $\begin{array}{l}\text { Correlation coefficient } \\
r\end{array}$ & $p \dagger$ \\
\hline IL-1a & $40.54 \pm 56.07$ & $16.2 \pm 11.88$ & 0.278 & 0.46 & 0.028 \\
\hline IL-1 $\beta$ & $7.6 \pm 16.30$ & $2.3 \pm 3.69$ & 0.734 & 0.76 & 0.001 \\
\hline IL-2 & $17.5 \pm 12.99$ & $11.6 \pm 7.82$ & 0.395 & 0.44 & 0.038 \\
\hline IL-4 & $10.3 \pm 13.6$ & $6.6 \pm 4.04$ & 0.962 & 0.56 & 0.009 \\
\hline IL-5 & $8.8 \pm 7.99$ & $9.2 \pm 4.92$ & 0.285 & 0.40 & 0.058 \\
\hline IL-6 & $24.4 \pm 10.65$ & $33.1 \pm 11.19$ & 0.095 & 0.64 & 0.002 \\
\hline IL-8 & $29.6 \pm 32.62$ & $19.1 \pm 8.87$ & 0.427 & 0.36 & 0.088 \\
\hline IL-10 & $2.6 \pm 1.83$ & $2.6 \pm 1.06$ & 0.792 & 0.70 & 0.001 \\
\hline IL-12p70 & $3.7 \pm 4.77$ & $2.3 \pm 1.35$ & 0.734 & 0.43 & 0.047 \\
\hline IL-13 & $9.3 \pm 4.80$ & $10.2 \pm 2.72$ & 0.193 & 0.52 & 0.014 \\
\hline GM-CSF & $28.3 \pm 12.98$ & $33.6 \pm 20.71$ & 0.734 & 0.37 & 0.076 \\
\hline GRO & $457.4 \pm 215.28$ & $381.1 \pm 149.52$ & 0.277 & 0.23 & 0.272 \\
\hline IFN- $\gamma$ & $293.1 \pm 103.77$ & $317.3 \pm 114.59$ & 0.651 & 0.21 & 0.329 \\
\hline MCP-1 & $951.8 \pm 265.13$ & $540.3 \pm 261.01$ & 0.003 & -0.03 & 0.903 \\
\hline MIP-1a & $679.1 \pm 525.50$ & $263.3 \pm 226.85$ & 0.041 & -0.51 & 0.807 \\
\hline MIP-1 $\beta$ & $32.9 \pm 27.1$ & $11.4 \pm 10.1$ & 0.034 & 0.29 & 0.180 \\
\hline MMP-9 & $151.4 \pm 111.58$ & $108.1 \pm 79.15$ & 0.343 & 0.18 & 0.393 \\
\hline RANTES & $2.9 \pm 3.76$ & $0.9 \pm 0.59$ & 0.343 & 0.65 & 0.002 \\
\hline TNFa & $977.0 \pm 401.35$ & $1140.8 \pm 377.42$ & 0.310 & 0.44 & 0.038 \\
\hline VEGF & $236.2 \pm 196.31$ & $106.3 \pm 30.41$ & 0.009 & - & - \\
\hline
\end{tabular}

WAMD wet age-related macular degeneration

* Mann-Whitney U test

† Spearman's rank correlation

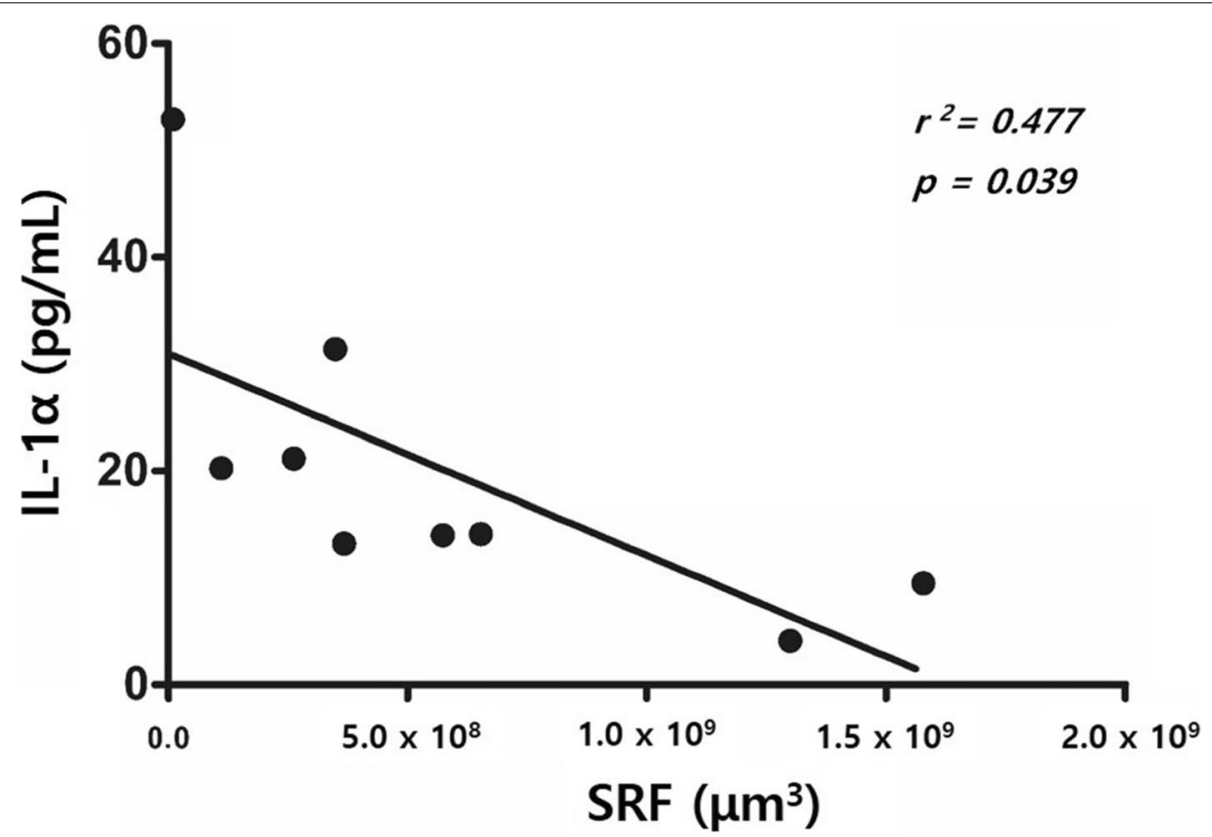

Fig. 2 Correlation between the volume of subretinal fluid (SRF) and IL-1a. There is a negative correlation between the level of IL-1a and the volume of SRF in the SRF-positive group 
Table 3 Levels of cytokine $(\mathrm{pg} / \mathrm{mL}$, mean $\pm \mathrm{SD})$ in the aqueous humor in wet age-related macular degeneration patients

\begin{tabular}{|c|c|c|c|c|c|c|c|c|c|}
\hline & \multicolumn{3}{|l|}{$\operatorname{SRF}(n=9)$} & \multicolumn{3}{|l|}{$\operatorname{PED}(n=8)$} & \multicolumn{3}{|l|}{$\mathrm{SRT}(n=8)$} \\
\hline & $(+)$ & $(-)$ & $P^{*}$ & $(+)$ & $(-)$ & $P^{*}$ & $(+)$ & $(-)$ & $\mathrm{P}^{*}$ \\
\hline IL-1a & $18.5 \pm 15.9$ & $216.3 \pm 199.5$ & 0.036 & $15.1 \pm 9.7$ & $170 \pm 192.6$ & 0.622 & $90.8 \pm 152.1$ & $17.9 \pm 8.7$ & 0.833 \\
\hline GM-CSF & $19.9 \pm 11.4$ & $71.0 \pm 67.4$ & 0.050 & $18.5 \pm 10.9$ & $72.9 \pm 65.6$ & 0.006 & $48.1 \pm 50.6$ & $14.7 \pm 13.4$ & 0.065 \\
\hline $\mathrm{IFN}-\gamma$ & $264.6 \pm 62.6$ & $676.6 \pm 611.8$ & 0.076 & $262.5 \pm 63.2$ & $681.4 \pm 607.3$ & 0.034 & $487.0 \pm 451.5$ & $238.4 \pm 43.2$ & 0.045 \\
\hline MCP-1 & $984.1 \pm 255.7$ & $854.4 \pm 266.1$ & 0.503 & $964.3 \pm 228.3$ & $899.1 \pm 343.3$ & 0.284 & $963.8 \pm 287.6$ & $913.0 \pm 710.1$ & 0.622 \\
\hline MIP-1a & $812.8 \pm 545.3$ & $330.9 \pm 127.6$ & 0.076 & $787.4 \pm 561.3$ & $388.1 \pm 190.6$ & 0.065 & $506.3 \pm 276.0$ & $917.7 \pm 710.1$ & 0.284 \\
\hline MIP-1 $\beta$ & $38.2 \pm 29.1$ & $21.3 \pm 13.0$ & 0.414 & $34.0 \pm 29.2$ & $30.7 \pm 20.2$ & 0.724 & $27.5 \pm 17.4$ & $41.9 \pm 36.5$ & 0.622 \\
\hline TNFa & $860.0 \pm 225.2$ & $1973.3 \pm 1399.3$ & 0.106 & $836.4 \pm 216.7$ & $2026.6 \pm 1343.3$ & 0.011 & $1409.4 \pm 1100.2$ & $871.6 \pm 295.3$ & 0.284 \\
\hline VEGF & $189.2 \pm 73.6$ & $349.3 \pm 327.7$ & 0.076 & $165.0 \pm 57.6$ & $403.8 \pm 289.9$ & 0.354 & $283.7 \pm 232.8$ & $166.0 \pm 60.5$ & 0.524 \\
\hline
\end{tabular}

VEGF vascular endothelial growth factor

*Mann-Whitney U test

Table 4 Comparison of optical coherence tomography (OCT) parameters between type 1 and type 2 macular neovascularization (MVN)

\begin{tabular}{llll}
\hline & Type 1 MNV $(\boldsymbol{n}=\mathbf{8})$ & Type 2 MNV $(\boldsymbol{n}=\mathbf{5})$ & $\boldsymbol{P}^{*}$ \\
\hline SRF volume $\left(\mu \mathrm{m}^{3}\right)$ & $505.04 \times 10^{6} \pm 373.83 \times 10^{6}$ & $315.56 \times 10^{6} \pm 472.61 \times 10^{6}$ & 0.284 \\
PED volume $\left(\boldsymbol{\mu m}^{3}\right)$ & $1151.58 \times 10^{6} \pm 2517.02 \times 10^{6}$ & $1711.82 \times 10^{6} \pm 3111.73 \times 10^{6}$ & 0.524 \\
SRT volume $\left(\boldsymbol{\mu m}^{3}\right)$ & $1655.24 \times 10^{6} \pm 2258.04 \times 10^{6}$ & $2238.47 \times 10^{6} \pm 3028.61 \times 10^{6}$ & 0.448 \\
CMT $(\boldsymbol{\mu m})$ & $377.00 \pm 91.49$ & $431.00 \pm 150.29$ & 0.724 \\
\hline
\end{tabular}

SRF subretinal fluid, PED pigment epithelial detachment, SRT subretinal tissue, CMT central macular thickness

* Mann-Whitney U test

mediators in the vitreous humor. Thus, the results of our study suggest that the eyes of patients with wet AMD showed increased MCP-1, MIP- $1 \alpha$, MIP-1 $\beta$, and VEGF concentrations in the vitreous.

MCP-1 is a potent chemotactic factor for monocytes and macrophages, and plays a critical role in angiogenesis and inflammatory processe s[17]. MCP-1 attracts macrophages into the $\mathrm{CNV}$ lesion and assists with digestion of the RPE and Bruch's membrane in the experimental model s[18, 19]. MCP-1 also induces angiogenesis by recruiting other cells, such as tumor-associated macrophages. These cells, in turn, release growth and angiogenic factors, such as VEG F[20]. Our results showed significantly elevated aqueous humor levels of MCP-1 in patients with $\mathrm{CNV}$ versus controls and were in agreement with those of previous studies. MIP- $1 \alpha$ and MIP- $1 \beta$ have been implicated in retinal inflammation, particularly in early T-cell-dependent stage s[21-23]. Their production by $\mathrm{T}$ lymphocytes entering the tissue is advantageous in many inflammatory situations because they amplify inflammatory cell recruitment. However, this cascade effect is likely to exacerbate predisposing factors in susceptible individual $\mathrm{s}[24]$. Consequently, $\mathrm{T}$ cell regulation of MIP- $1 \alpha$ and MIP-1 $\beta$ production is important. An in vitro study has shown that RPE cells downregulate the levels of CCL3(MIP-1 $\alpha$ ) and CCL4(MIP-1 $\beta$ ) production by $\mathrm{T}$ lymphocytes using the soluble mediators $\mathrm{SCD} 54$ and prostaglandin E2 (PGE2) [24]. Yang et al. found that MIP1a expression increased in the corneal neovascularization tissue of mice, suggesting that MCP-1 and MIP-1a is related to inflammation and neovascularizatio $\mathrm{n}$ [25]. In addition, it was confirmed that MIP-1a was significantly increased in a study targeting the laser-induced CNV mouse model. MIP-1a was significantly correlated with the CNV lesion area, suggesting that the migration of MIP-1a-mediated macrophages could induce an inflammatory response and affect $\mathrm{CNV}$ formatio $\mathrm{n}$ [26]. Our novel results showed elevated aqueous humor concentrations of MIP- $1 \alpha$ and MIP- $1 \beta$ in eyes with wet AMD. We believe that these findings are attributed to a disrupted RPE cell regulation because of degeneration and suggest that inflammatory factors may influence the pathogenesis of AM D[27]..

Quantitative analysis of OCT images is useful for the treatment strategy selection and for monitoring the biological response to treatment. It is possible to characterize individual MNV lesions according to the presence or number of sub-components. This could help investigate MNV heterogeneous lesions. Unfortunately, there is a lack of a reliable correlation between the role of 
Table 5 Levels of significant cytokines $(\mathrm{pg} / \mathrm{mL}$, mean $\pm \mathrm{SD})$ in the aqueous humor among the 3 groups

\begin{tabular}{|c|c|c|c|}
\hline & Control $(n=10)$ & Type $1(n=8)$ & Type $2(n=5)$ \\
\hline IFN- $\gamma$ & $317.3 \pm 114.59$ & $247.3 \pm 46.7$ & $621.9 \pm 542.5$ \\
\hline $\begin{array}{l}\text { p value versus } \\
\text { controls }\end{array}$ & - & 0.460 & 0.129 \\
\hline $\begin{array}{l}\text { p value versus } \\
\text { type } 1\end{array}$ & - & - & 0.006 \\
\hline MCP-1 & $540.3 \pm 261.01$ & $1003.5 \pm 209.2$ & $849.4 \pm 317.3$ \\
\hline $\begin{array}{l}\text { p value versus } \\
\text { controls }\end{array}$ & - & 0.001 & 0.040 \\
\hline $\begin{array}{l}\text { p value versus } \\
\text { type } 1\end{array}$ & - & - & 0.284 \\
\hline MIP-1a & $263.3 \pm 226.85$ & $842.1 \pm 573.8$ & $380.4 \pm 166.0$ \\
\hline $\begin{array}{l}p \text { value versus } \\
\text { controls }\end{array}$ & - & 0.021 & 0.206 \\
\hline $\begin{array}{l}\text { p value versus } \\
\text { type } 1\end{array}$ & - & - & 0.065 \\
\hline MIP-1 $\beta$ & $11.4 \pm 10.1$ & $37.2 \pm 29.5$ & $26.3 \pm 20.1$ \\
\hline $\begin{array}{l}p \text { value versus } \\
\text { controls }\end{array}$ & - & 0.012 & 0.129 \\
\hline $\begin{array}{l}\text { p value versus } \\
\text { type } 1\end{array}$ & - & - & 0.724 \\
\hline TNFa & $1140.8 \pm 377.42$ & $836.4 \pm 231.6$ & $1788.4 \pm 1279.4$ \\
\hline $\begin{array}{l}\text { p value versus } \\
\text { controls }\end{array}$ & - & 0.274 & 0.440 \\
\hline $\begin{array}{l}\text { p value versus } \\
\text { type } 1\end{array}$ & - & - & 0.019 \\
\hline VEGF & $106.3 \pm 30.41$ & $168.8 \pm 60.3$ & $350.0 \pm 278.4$ \\
\hline $\begin{array}{l}\text { p value versus } \\
\text { controls }\end{array}$ & - & 0.083 & 0.040 \\
\hline $\begin{array}{l}\text { p value versus } \\
\text { type } 1\end{array}$ & - & - & 0.354 \\
\hline
\end{tabular}

VEGF vascular endothelial growth factor

${ }^{*}$ Mann-Whitney U test

intraocular cytokines and OCT-based parameters. We analyzed the differences in cytokine levels between wet AMD patients with SRF or PED and those without SRF or PED.

As described in the results, patients with MNV and SRF showed low concentrations of proinflammatory cytokines, such as IL- $1 \alpha$ and GM-CSF. IL- $1 \alpha$ is a proinflammatory cytokine that derives macrophages and induces acute inflammatio $n[28]$. Pathologically, IL-1 $\alpha$ can stimulate RPE cells to secrete GM-CSF, which is a potent chemoattractant that recruits macrophages to the retina. IL-1 $\alpha$ is also implicated in the pathogenesis of CNV. Blocking IL-1 $\alpha$ receptors could inhibit the development of CNV in an experimental animal mode 1[29]. Therefore, lower intraocular concentrations of IL- $1 \alpha$ indicate lower levels of inflammation in CNV pathogenesis. Our results indicate that SRF may be associated with a positive prognosis because we found relatively low levels of proinflammatory cytokines in the SRF-positive group. Other studies have found that SRF may be associated with a benign disease course in patients with $\mathrm{CNV}$ lesion s[7]. Moreover, in the SRF-positive group, we found a negative correlation between the concentration of IL- $1 \alpha$ and the volume of SRF (Fig. 2). A potential explanation for this correlation is that SRF could be suggestive of a functional providing RPE and photoreceptor survival, in contrast to vascular atrophy in the sub-RPE space. The presence of SRF may be suggestive of a less aggressive, perhaps even supportive, stage of $\mathrm{CNV}$, rather than advanced destructive neurosensory ingrowth associated with intraretinal exudation. This is supported by the fact that treatment-refractory SRF was not detrimental to the vision outcome in a recent stud y[7]. Interestingly, positive effects of SRF on the visual outcome have also been reported in diabetic macular edema and retinal vein occlusio $\mathrm{n}[30,31]$..

In the presence of PED on OCT, it was confirmed that IFN- $\gamma$ and TNF- $\alpha$ values were significantly lower than those of the group without PED. In other animal studies, it has been argued that they may help maintain the outer blood-retinal barrier by providing fluid transport in RPE cell s[32, 33]. Therefore, through the results of this study, it can be considered that PED may occur due to a decrease in these cytokines. Significantly smaller values were also measured in the type $1 \mathrm{MNV}$ group than in the type $2 \mathrm{MNV}$ group, and it is thought that additional research is needed on this result.

Our findings suggest that angiographic classification may be an important clue to determine the treatment strategy. Patients with type $1 \mathrm{MNV}$ showed increased levels of MCP-1, MIP- $1 \alpha$, and MIP-1 $\beta$, but not VEGF, compared to those with type $2 \mathrm{MNV}$. These results suggest that in patients with type $1 \mathrm{MNV}$, inhibition of VEGF alone may not be a sufficient treatment. The levels of VEGF and angiogenic inflammatory cytokines were not significantly increased in patients with type $1 \mathrm{MNV}$ compared with the control group. Inhibition of the MCP-1, MIP- $1 \alpha$, and MIP- $1 \beta$ related cascade may be a promising advance in MNV treatment, especially for patients with type $1 \mathrm{MNV}$. Considering that platelet-derived growth factor (PDGF) is the main growth factor that stimulates the secretion of MCP-1,[34] PDGF inhibition could be a promising treatment for MNV, particularly in patients with type $1 \mathrm{MNV}$.

Moreover, we confirmed that the VEGF concentration of aqueous humor in type $2 \mathrm{MNV}$ was higher than that of type $1 \mathrm{MNV}$ or in the control group. It is thought that type $2 \mathrm{MNV}$ patients have a higher VEGF concentration in the vitreous cavity and anterior chamber due to the growth of neovascularization in the subretina, and that their prognosis is worse. In fact, several studies also found that, after anti-VEGF injection treatment, type 
$2 \mathrm{MNV}$ patients showed worse visual acuity and a poor responsiveness to injection when compared to type 1 MNV patient s[35, 36]..

A limitation of this study is that the sample size was small; therefore, a larger multicenter prospective randomized study is required to clarify the effects of inflammatory factors in AMD. In addition, it would be good to analyze the sample size larger to confirm the correlation between quantitative data of OCT and aqueous humor cytokine. Moreover, since factors such as SRF and PED may be temporary, additional studies are needed to confirm the change in cytokine concentration according to changes in these factors after injection treatment in the same patient.

\section{Conclusions}

In conclusion, inflammatory cytokines varied according to the type of AMD- and OCT-based parameters. Our observation of low levels of VEGF in patients with type $1 \mathrm{MNV}$ implies that the inhibition of VEGF alone appears to be insufficient treatment for these patients and that cytokines such as MCP- 1 , MIP- $1 \alpha$, and MIP- $1 \beta$ should be modulated. And the presence of SRF in MNV may be associated with a positive prognosis because we found relatively low levels of proinflammatory cytokines. Understanding the pathological mechanisms of angiogenesis and the cytokines involved is necessary to identify new therapeutic targets for patients with neovascular diseases.

\begin{abstract}
Abbreviations
AMD: Age-related macular degeneration; VEGF: Vascular endothelial growth factor; CNV: Choroidal neovascularization; OCT: Optical coherence tomography; MNV: Macular neovascularization; FA: Fluorescein angiography; logMAR: Logarithm of the Minimum Angle of Resolution; SRF: Subretinal fluid; PED: Pigment epithelial detachments; SRT: Subretinal tissue; RPE: Retinal pigment epithelium; CMT: Central macular thickness; PDGF: Platelet-derived growth factor.
\end{abstract}

\section{Supplementary Information}

The online version contains supplementary material available at https://doi. org/10.1186/s12886-021-02152-6.

Additional file 1. Spectral-domain optical coherence tomography scan showing subretinal tissue. Spectral-domain optical coherence tomography scan showing subretinal tissue (SRT), which includes subretinal highly reflective material and fibrovascular RPE detachment.

\section{Acknowledgements}

We would like to thank Editage (www.editage.co.kr) for English language editing.

\section{Authors' contributions}

Jin-Ho Joo and Hyejee Kim contributed equally to this work. These authors are co-first author. J.H.J. and H.K. contributed to the data acquisition, analysis, and interpretation of this work; and participated in drafting and revising the contents of the study. J.H.S. contributed to the data acquisition and analysis.
S.W.M contributed to the concept of this work and approved the submission of the final version. All authors have read and approved the manuscript.

\section{Funding}

This research was supported by the National Research Foundation of Korea (NRF), funded by the Ministry of Science and ICT (2018M3A9E8078812) and Kyung Hee University (KHU-20191225).

\section{Availability of data and materials \\ Not applicable.}

\section{Declarations}

\section{Ethics approval and consent to participate}

The current research followed the tenets of the Declaration of Helsinki, and all patients provided informed consent after an explanation of the study protocol. The Institutional Review Board at Kyung Hee University Hospital at Gangdong (KHNMC-2015-07-042) approved this prospective study.

\section{Consent for publication}

Not applicable.

\section{Competing interests}

None

\section{Author details}

1Department of Ophthalmology, Kyung Hee University Hospital at Gangdong, 892 Dongnam-ro, Gangdong-gu, Seoul, Republic of Korea. ${ }^{2}$ Barunbit EYE Clinic, Seoul, Republic of Korea.

Received: 7 July 2021 Accepted: 18 October 2021

Published online: 18 November 2021

\section{References}

1. Rosenfeld PJ, Brown DM, Heier JS, Boyer DS, Kaiser PK, Chung CY, et al. Ranibizumab for neovascular age-related macular degeneration. N Engl J Med. 2006;355(14):1419-31.

2. Kvanta A, Algvere PV, Berglin L, Seregard S. Subfoveal fibrovascular membranes in age-related macular degeneration express vascular endothelial growth factor. Invest Ophthalmol Vis Sci. 1996;37(9):1929-34.

3. Grossniklaus HE, Ling JX, Wallace TM, Dithmar S, Lawson DH, Cohen C, et al. Macrophage and retinal pigment epithelium expression of angiogenic cytokines in choroidal neovascularization. Mol Vis. 2002;8:119-26.

4. Ferrara N. Vascular endothelial growth factor: basic science and clinical progress. Endocr Rev. 2004;25(4):581-611.

5. Amoaku WM, Chakravarthy U, Gale R, Gavin M, Ghanchi F, Gibson J, et al. Defining response to anti-VEGF therapies in neovascular AMD. Eye (London, England). 2015;29(6):721-31.

6. Lux A, Llacer H, Heussen FM, Joussen AM. Non-responders to bevacizumab (Avastin) therapy of choroidal neovascular lesions. Br J Ophthalmol. 2007;91(10):1318-22.

7. Schmidt-Erfurth U, Waldstein SM. A paradigm shift in imaging biomarkers in neovascular age-related macular degeneration. Prog Retin Eye Res. 2016;50:1-24

8. Katsura Y Okano T, Matsuno K Osako M, Kure M, Watanabe T, et al. Erythropoietin is highly elevated in vitreous fluid of patients with proliferative diabetic retinopathy. Diabetes Care. 2005;28(9):2252-4.

9. Takeda A, Baffi JZ, Kleinman ME, Cho WG, Nozaki M, Yamada K, et al. CCR3 is a target for age-related macular degeneration diagnosis and therapy. Nature. 2009;460(7252):225-30.

10. Robbins SG, Mixon RN, Wilson DJ, Hart CE, Robertson JE, Westra I, et al. Platelet-derived growth factor ligands and receptors immunolocalized in proliferative retinal diseases. Invest Ophthalmol Vis Sci. 1994:35(10):3649-63.

11. Jonas JB, Degenring RF, Kreissig I, Friedemann T, Akkoyun I. Exudative age-related macular degeneration treated by intravitreal triamcinolone acetonide. A prospective comparative nonrandomized study. Eye (London, England). 2005;19(2):163-70. 
12. Macular Photocoagulation Study Group. Subfoveal neovascular lesions in age-related macular degeneration. Guidelines for evaluation and treatment in the macular photocoagulation study. Arch Ophthalmol (Chicago, III : 1960). 1991;109(9):1242-57.

13. Folgar FA, Jaffe GJ, Ying GS, Maguire MG, Toth CA. Comparison of optical coherence tomography assessments in the comparison of age-related macular degeneration treatments trials. Ophthalmology. 2014;121(10):1956-65.

14. Funatsu $H$, Yamashita $H$, Noma H, Mimura T, Nakamura S, Sakata K, et al. Aqueous humor levels of cytokines are related to vitreous levels and progression of diabetic retinopathy in diabetic patients. Graefe's Arch Clin Exp Ophthalmol. 2005;243(1):3-8.

15. Noma H, Funatsu H, Yamasaki M, Tsukamoto H, Mimura T, Sone T, et al. Aqueous humour levels of cytokines are correlated to vitreous levels and severity of macular oedema in branch retinal vein occlusion. Eye (London, England). 2008;22(1):42-8

16. Butler DC, Schandl C, Hyer M, Erin Presnell S. Aqueous fluid as a viable substitute for vitreous fluid in postmortem chemistry analysis. J Forensic Sci. 2020;65(2):508-12.

17. Suzuki M, Kamei M, Itabe H, Yoneda K, Bando H, Kume N, et al. Oxidized phospholipids in the macula increase with age and in eyes with agerelated macular degeneration. Mol Vis. 2007;13:772-8.

18. Yamada K, Sakurai E, Itaya M, Yamasaki S, Ogura Y. Inhibition of laserinduced choroidal neovascularization by atorvastatin by downregulation of monocyte chemotactic protein-1 synthesis in mice. Invest Ophthalmol Vis Sci. 2007;48(4):1839-43.

19. Austin BA, Liu B, Li Z, Nussenblatt RB. Biologically active fibronectin fragments stimulate release of MCP-1 and catabolic cytokines from murine retinal pigment epithelium. Invest Ophthalmol Vis Sci. 2009;50(6):2896-902.

20. O'Hayre M, Salanga CL, Handel TM, Allen SJ. Chemokines and cancer: migration, intracellular signalling and intercellular communication in the microenvironment. Biochem J. 2008;409(3):635-49.

21. Ishikawa K, Yoshida S, Kadota K, Nakamura T, Niiro H, Arakawa S, et al. Gene expression profile of hyperoxic and hypoxic retinas in a mouse model of oxygen-induced retinopathy. Invest Ophthalmol Vis Sci. 2010;51(8):4307-19.

22. Yoshida S, Yoshida A, Ishibashi T, Elner SG, Elner VM. Role of MCP-1 and MIP-1alpha in retinal neovascularization during postischemic inflammation in a mouse model of retinal neovascularization. J Leukoc Biol. 2003;73(1):137-44.

23. Foxman EF, Zhang M, Hurst SD, Muchamuel T, Shen D, Wawrousek EF, et al. Inflammatory mediators in uveitis: differential induction of cytokines and chemokines in Th1- versus Th2-mediated ocular inflammation. J Immunol (Baltimore, Md : 1950). 2002;168(5):2483-92.
24. Wallace CA, Moir G, Malone DF, Duncan L, Devarajan G, Crane IJ. Regulation of T-lymphocyte CCL3 and CCL4 production by retinal pigment epithelial cells. Invest Ophthalmol Vis Sci. 2013;54(1):722-30.

25. Yang Q, Zhang Y, Liu X, Wang N, Song Z, Wu K. A Comparison of the Effects of Benzalkonium Chloride on Ocular Surfaces between C57BL/6 and BALB/c Mice. Int J Mol Sci. 2017;18(3):509.

26. Wang C, Zhang R, Zhang Q, Jin H, Wei C, Wu C, et al. Cytokine profiles and the effect of intravitreal Aflibercept treatment on experimental choroidal neovascularization. Ophthalmic Res. 2020. https://doi.org/10.1159/00051 3588 .

27. Kauppinen A, Paterno JJ, Blasiak J, Salminen A, Kaarniranta K. Inflammation and its role in age-related macular degeneration. Cell Mol Life Sci. 2016;73(9):1765-86.

28. Dinarello CA. The biology of interleukin-1. Chem Immunol. 1992;51:1-32.

29. Zou Y, Xu X, Chiou GC. Effect of interleukin-1 blockers, CK112, and CK116 on rat experimental choroidal neovascularization in vivo and endothelial cell cultures in vitro. J Ocul Pharmacol Ther. 2006;22(1):19-25.

30. Lloyd Clark W, Liu M, Kitchens J, Wang PW, Haskova Z. Baseline characteristics associated with early visual acuity gains after ranibizumab treatment for retinal vein occlusion. BMC Ophthalmol. 2019;19(1):11.

31. Sophie R, Lu N, Campochiaro PA. Predictors of functional and anatomic outcomes in patients with diabetic macular edema treated with Ranibizumab. Ophthalmology. 2015;122(7):1395-401.

32. Li R, Maminishkis A, Banzon T, Wan Q, Jalickee S, Chen S, et al. IFN \{gamma\} regulates retinal pigment epithelial fluid transport. Am J Physiol Cell Physiol. 2009;297(6):C1452-65.

33. Shi G, Maminishkis A, Banzon T, Jalickee S, Li R, Hammer J, et al. Control of chemokine gradients by the retinal pigment epithelium. Invest Ophthalmol Vis Sci. 2008;49(10):4620-30.

34. Sridhar P, Liu Y, Chin LD, Borja CE, Mann M, Skopicki HA, et al. Plateletderived growth factor-stimulated expression of the MCP-1 immediateearly gene involves an inhibitory multiprotein complex. Mol Cell Biol. 1999;19(6):4219-30.

35. Invernizzi A, Nguyen V, Teo K, Barthelmes D, Fung A, Vincent A, et al. Five-year real-world outcomes of occult and classic choroidal neovascularization: data from the fight retinal blindness! Project. Am J Ophthalmol. 2019;204:105-12.

36. Steinle NC, Du W, Gibson A, Saroj N. Outcomes by baseline choroidal neovascularization features in age-related macular degeneration: a post hoc analysis of the VIEW studies. Ophthalmol Retina. 2020;5:141-50.

\section{Publisher's Note}

Springer Nature remains neutral with regard to jurisdictional claims in published maps and institutional affiliations.
Ready to submit your research? Choose BMC and benefit from:

- fast, convenient online submission

- thorough peer review by experienced researchers in your field

- rapid publication on acceptance

- support for research data, including large and complex data types

- gold Open Access which fosters wider collaboration and increased citations

- maximum visibility for your research: over $100 \mathrm{M}$ website views per year

At BMC, research is always in progress.

Learn more biomedcentral.com/submissions 